\title{
Periostin in bronchial asthma - a brief update
}

\author{
Adriana Grigoras ${ }^{* 1,2}$, Ludmila Lozneanu ${ }^{1}$, Constantin Cristian Grigoras ${ }^{3}$, Simona \\ Eliza Giusca ${ }^{1}$, Irina Draga Caruntu ${ }^{1}$, Cornelia Amalinei ${ }^{1,2}$
}

'Department of Morphofunctional Sciences I, "Grigore T. Popa" University of Medicine and Pharmacy, lasi, Romania, ${ }^{2}$ Institute of Legal Medicine lasi, Romania, ${ }^{3}$ Specialty Ambulatory, Pneumology Clinic Hospital, lasi, Romania

\begin{abstract}
Periostin is an extracellular matrix protein which intervenes in the regulation of angiogenesis, and in tumoral cells proliferation and invasion. Recent studies, mainly experimental models, have demonstrated the intervention of this molecule in asthmatic disease, by eosinophils recruitment, bronchial wall remodeling, and by stimulation of inflammatory cytokines production. Currently, periostin is considered a marker of type 2 inflammation in asthma, being secreted by respiratory epithelial cells triggered by IL-13 and IL-4. Concomitantly, periostin accumulated at the bronchial epithelial-connective tissue interface is involved in fibrogenesis and mucus secretion, in correlation with the intensity of bronchial mucosa eosinophilic inflammatory infiltrate. However, the intimate molecular mechanisms of periostin involvement in the pathogenic pathway of asthmatic diseases is far away from elucidation, further research being necessary to certify its value as a biomarker useful in diagnosis and in establishment of therapeutic schemes in bronchial asthma.
\end{abstract}

Keywords: periostin, bronchial asthma, allergic inflammation

\section{Introduction}

Periostin (osteoblast-specific factor-2), member of the fasciclin-containing protein family, was firstly described in 1993, as an extracellular matrix protein of $93.3 \mathrm{kDa}$. Periostin is produced by mesenchymal cells line (osteoblasts, osteoblast-derived cells, the periodontal ligament, and periosteum), in adult mice [1].

Periostin structure comprises 836-amino acid and an EMI (EMILIN-like) domain adjacent to $\mathrm{N}$ terminal end, a tandem of four FAS1 (fasciclin) domains aligned in the middle, and splicing domains at the $\mathrm{C}$

Received: January 2017; Accepted after review: March 2017; Published: March 2017.

*Corresponding author: Grigoras Adriana, Department of Morphofunctional Sciences I, University of Medicine and Pharmacy "Grigore T. Popa", Institute of Legal Medicine, Buna Vestire Street, 700455 Iasi, Romania.

E-mail: a grigoras6600@yahoo.com terminus. EMI domain allows collagen type I and fibronectin recognition, while FAS1 central domains are able to bind to tenascin- $C$ or to bone morphogenetic protein (BMP)-1 [2, 3].

The results of numerous studies have demonstrated that periostin is expressed in a large variety of adult and fetal tissues, such as embryonic periosteum, periodontal ligament, placenta, cardiac valve, lung, adrenal, and thyroid glands [4].

Periostin is encoded by POSTN gene in humans. Periostin has been initially thought to act as a ligand of alpha- $\mathrm{V} /$ beta- 3 and alphaV/beta-5 integrins, molecules which regulate epithelial cells adhesion and migration [5]. Later on, the intervention of this protein in bone tissue development, odontogenesis, heart valvular apparatus, post myocardial infarction remodeling, carcinogenesis [4, 6-8], and last but not least, allergic diseases development, such as eosinophilic esophagitis, atopic dermatitis, or allergic rhinitis has been demonstrated [9-11]. 
Recent data have shown periostin intervention in lung idiopathic diseases and in characteristic bronchial inflammatory and remodeling processes of asthmatic disease, by interaction with other extracellular matrix molecules, at the epithelial-connective tissue interface $[12,13]$.

\section{Periostin and bronchial asthma}

Bronchial asthma is a chronic inflammatory disease affecting more than 334 million people all over the world [14]. The involvement of periostin in type II inflammatory reaction is currently under intense study, in order to improve the therapeutic means in asthmatic disease, mainly in patients diagnosed with severe type of bronchial asthma, with unfavorable response to corticosteroid therapy.

An immunohistochemical study performed more than a decade ago had been the first one to demonstrate the presence of periostin deposits in thickened basement membrane of the respiratory epithelium in asthmatic patients [15]. Nowadays, it is well recognized that the thickening of the epithelial-connective tissue interface in asthma is the consequence of excessive deposits of collagen types I, III, and $\mathrm{V}$, associated to fibronectin and tenascin-C. Periostin identification in the same location as these extracellular matrix protein supports the assertion that they represent different components of the bronchial subepithelial fibrosis $[9,16]$.

These initial observations have been later completed by other studies which revealed an increased periostin serum or sputum level in patients with allergic bronchial asthma [12, 17, 18].

Thus, an increased periostin level associated with eosinophilia and Th2 mediated inflammation is seen in a specific type of bronchial asthma. Activated Th2 cells are able to produce several inflammatory cytokines, such as IL-4 and IL-13, as the main activators of periostin gene expression in the bronchial wall in asthmatic disease $[13,19]$.

These data are also supported by the results of another study performed on asthmatic patients type "Th2-high", in which IL13 has been associated with an increased
serpinB2, Clca1 and POSTN gene expression in airway epithelial brushings [20, 21]. An increased eosinophilic inflammation in bronchial mucosa has been also noticed, in association with respiratory epithelium basement membrane thickening, and a fast decline of lung function despite the aggressive corticosteroid therapy. As a result of these observations, periostin has been considered as a potential predictive biomarker of anti-IL13 therapy utility.

Respiratory epithelium cells are not the only type responsible for periostin production, as other bronchial wall cells are involved in its synthesis, such as eosinophils, macrophages $[22,23]$ or fibroblasts stimulated by TGF- $\beta$ [24].

Biopsies of the bronchial mucosa of patients with allergic bronchial asthma have been revealing an infiltration of eosinophils, associated with mast cells and T cells, mainly Th2 cells. It appears that periostin enhanced expression is responsible for the induction of eosinophils recruitment in bronchial wall [12] and its ability to act as $\alpha_{v} \beta_{3}, \alpha_{v} \beta_{5}, \alpha_{4} \beta_{6}$, and $\alpha_{M} \beta_{2}$ (CD11b) integrin ligand increases eosinophils adherence to fibronectin [25-27].

Periostin is also able to activate $T$ cells and their differentiation into Th2 or neutrophils recruitment in bronchial mucosa $[25,28]$. Activated Th2 cells produce also IL-5 which intervenes in eosinophilic line development. The importance of this IL-5 has been firstly noticed in 1990's in IL-5 knockout mice [29]. However, the reduction of eosinophilic infiltration of the bronchial wall following antiIL-5 antibodies therapy has not been associated with a significant improvement of the respiratory function, due to the complexity of factors involved in asthmatic disease pathogeny [30].

As a conclusion of all these observations, periostin is considered as a factor that protracts bronchial mucosa Th2 cells and eosinophils inflammation and aggravates bronchial wall remodeling in severe type of asthma [16, 31].

Moreover, the data accumulated until now have demonstrated a direct relationship between periostin serum level and eosinophilia, emerging as a surrogate marker of Th2 inflammation in asthma and may 
become one of the predictive factors of new therapy efficiency, e.g. lebrikizumab (anti-IL-13 antibody) [13]. This final feature is also supported by the results of studies which demonstrated a higher efficiency of lebrikizumab therapy in asthmatic patients with increased periostin serum level, compared to patients with a low level of serum periostin [32, 33].

Periostin intervention in bronchial wall is not limited to inflammatory cells chemoattraction and activation. It is also involved in the regulation of mucus secretion performed by goblet cells of the respiratory bronchial epithelium, by inhibition Gob5 (putative calcium-activated chloride channel involved in the regulation of mucus production) expression and by binding to integrins $\alpha 4$ and $\beta 1 / 2$ and induction of activation of intracellular pathways resulting in the reduction of the expression of transcription factors, such as NF-KB, Sp1, and AP-1 [34, 35].

Moreover, experimental studies have revealed that the lack of periostin induces a goblet cell hyperplasia in respiratory epithelium [34] and, consequently, a mucus hypersecretion. Thus, periostin may contribute to the enhancement of the mucus secretion in respiratory epithelium (Figure 1).

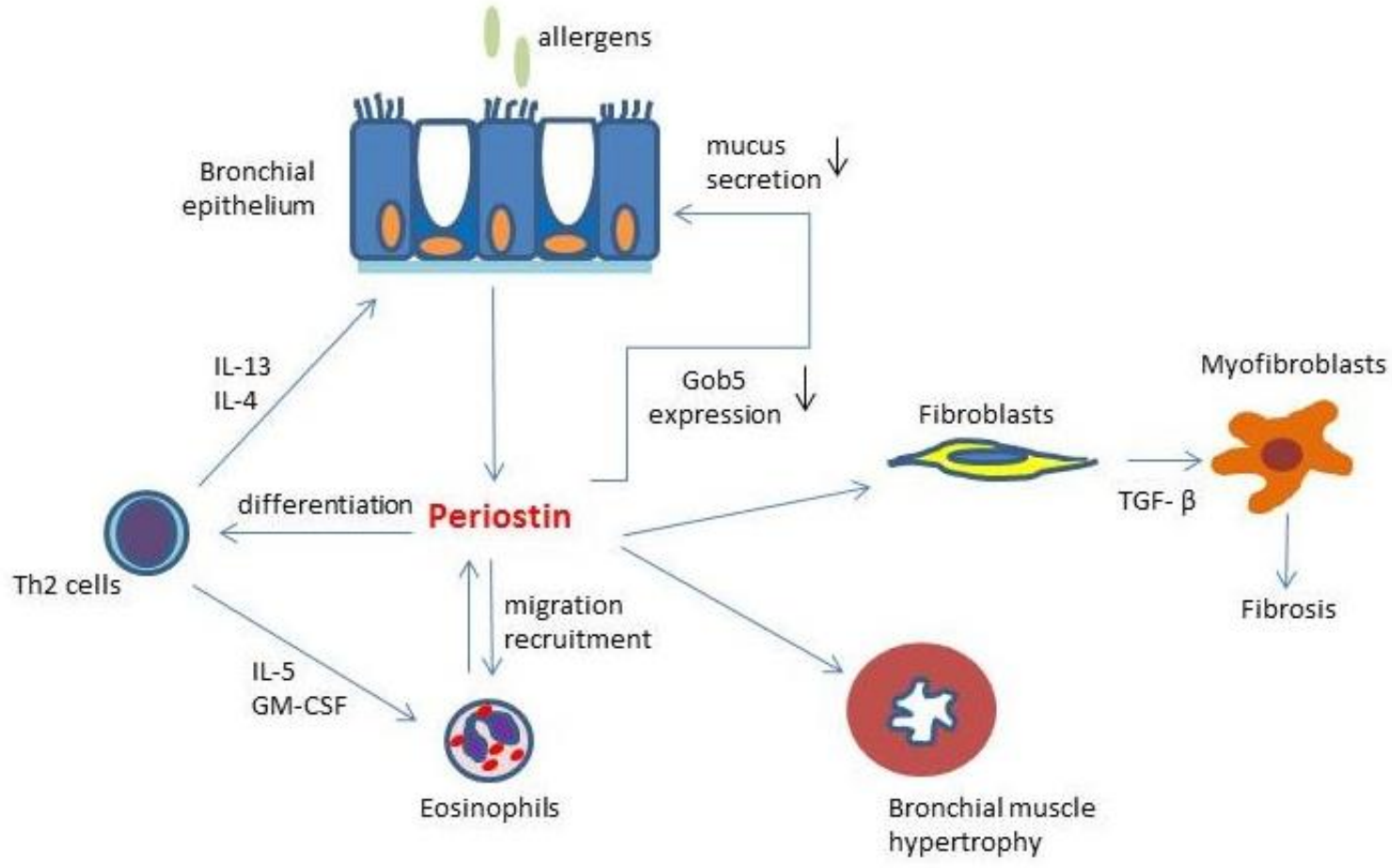

Fig. 1. The roles of periostin in the pathogenic process of asthma

Not the last, periostin stimulates bronchial muscle hypertrophy and increases contractile proteins expression, thus facilitating bronchospasm as a characteristic feature of asthma crises [25].

Compared to adult serum periostin values which are correlated with Th2 cytokines (IL-13 and IL-5) and with bronchial eosinophilic inflammation, in asthmatic children there is a slight periostin serum increase, 76.0 (65.091.8) $\mathrm{ng} / \mathrm{mL}$ compared to normal concentration in peripheral blood, 71.0 (57.580.0) $\mathrm{ng} / \mathrm{mL}$, though without a correlation with bronchial eosinophilic inflammation and with FeNO (fractional exhaled nitric oxide) values [36].

A decrease in periostin level has been also noticed after puberty [37]. This is probably related to the decreases of length growth, the increased periostin serum values in small childhood being mainly related to its secretion in bone tissue [37]. As a consequence, 
periostin serum values are now considered useless in children for bronchial asthma therapy management, even more as its serum value is variable according to the age.

Despite all the data accumulated during the last years of research, periostin role in bronchial asthma pathogenesis is far away from being elucidated, all the more as fibrobronchoscopy and transbronchial intrapulmonary biopsy in evaluation of bronchial asthma patients is limited. Furthermore, periostin dosage kits are currently used only for research purposes [14]. Taking all these considerations into account, periostin values are exposed to multiple variables.

However, according to the last year literature review, an approach to the validation of stable, precise methods of serum periostin dosage, e.g. Elecsys $\AA$ periostin immunoassay [14] and ARCHITECT Periostin Immunoassay [19], is currently developed, as potential

\section{References}

1. Takeshita S, Kikuno $\mathrm{R}$, Tezuka $\mathrm{K}$, et al. Osteoblast-specific factor 2: cloning of a putative bone adhesion protein with homology with the insect protein fasciclin I. Biochem $J$ 1993; 294(Pt 1):271-278.

2. Maruhashi T, Kii I, Saito M, et al. Interaction between periostin and BMP-1 promotes proteolytic activation of lysyloxidase. $\mathrm{J} \mathrm{Biol}$ Chem 2010; 285(17):13294-13303.

3. Kii I, Nishiyama T, Li M, et al. Incorporation of tenascin- $C$ into the extracellular matrix by periostin underlies an extracellular meshwork architecture. J Biol Chem 2010; 285 (3):20282039.

4. Nuzzo PV, Buzzatti G, Ricci F, et al. Periostin: a novel prognostic and therapeutic target for genitourinary cancer? Clin Genitourin Cancer 2014; 12(5):301-311.

5. Conway SJ, Izuhara K, Kudo Y, et al. The role of periostin in tissue remodeling across health and disease. Cell Mol Life Sci 2014; 71(7):1279-1288.

6. Zhu M, Fejzo MS, Anderson L, et al. Periostin promotes ovarian cancer angiogenesis and metastasis. Gynecol Oncol 2010; 119(2):337344.

7. Kusumoto D, Fukuda K. The role of angiogenetic factors in the pathogenesis and methods to be introduced in asthmatic disease diagnosis scheme.

\section{Conclusions}

The current data regarding periostin intervention in human asthmatic disease are limited. However, research results have been supporting so far the possibility to use periostin as a biomarker of Th2 inflammation in bronchial allergic asthma, as its serum level is correlated with the amplitude of bronchial wall remodeling in corticoresistant patients. Thus, the evaluation of periostin serum level may be a valuable tool in the evaluation of anti-inflammatory therapy efficiency in bronchial asthma.

\section{Conflict of interest}

Authors declare no conflicts of interest.

the progression of cardiac valve disease. Clin Calcium 2013; 23(4):481-488.

8. Idolazzi L, Ridolo E, Fassio A, et al. Periostin: The bone and beyond. Eur J Intern Med 2016; S0953-6205(16)30412-5.

9. Izuhara K, Arima K, Ohta S, et al. Periostin in allergic inflammation. Allergol Int 2014; 63(2):143-151.

10. Arima K, Ohta $S$, Takagi $A$, et al. Periostin contributes to epidermal hyperplasia in psoriasis common to atopic dermatitis. Allergol Int 2015; 64(1):41-48.

11. Rothenberg ME, Wen $T$, Greenberg $A$, et al. Intravenous anti-IL-13 mAb QAX576 for the treatment of eosinophilic esophagitis. J Allergy Clin Immunol 2015; 135(2):500-507.

12. Li $W$, Gao $P$, Zhi $Y$, et al. Periostin: its role in asthma and its potential as a diagnostic or therapeutic target. Respir Res 2015; 16:57.

13. Izuhara K, Ohta S, Ono J. Using Periostin as a Biomarker in the Treatment of Asthma. Allergy Asthma Immunol Res 2016; 8(6):491-498.

14. Palme $\mathrm{S}$, Christenson $\mathrm{RH}$, Jortani $\mathrm{SA}$, et al. Multicenter evaluation of analytical characteristics of the Elecsys ${ }^{\circledR}$ Periostin immunoassay. Clin Biochem 2016; S00099120(16)30376-9. 
15. Takayama G, Arima $K$, Kanaji $T$, et al. Periostin: A novel component of subepithelial fibrosis of bronchial asthma downstream of IL-4 and IL-13 signals. J Allergy Clin Immunol 2006; 118(1):98-104.

16. Kanemitsu $Y$, Matsumoto $H$, Mishima $M$, et al. Factors contributing to an accelerated decline in pulmonary function in asthma. Allergol Int 2014; 63(2):181-188.

17. Parulekar AD, Atik MA, Hanania NA. Periostin, a novel biomarker of TH2-driven asthma. Curr Opin Pulm Med 2014; 20(1):60-65.

18. Johansson MW, Annis DS, Mosher DF. $\alpha M \beta 2$ integrin-mediated adhesion and motility of IL-5stimulated eosinophils on periostin. $A m \mathrm{~J}$ Respir Cell Mol Biol 2013; 48(4):503-510.

19. Jeanblanc NM, Hemken PM, Datwyler MJ, et al. Development of a new ARCHITECT automated periostin immunoassay. Clin Chim Acta 2017; 464:228-235.

20. Matsusaka $M$, Kabata $H$, Fukunaga $K$, et al. Phenotype of asthma related with high serum periostin levels. Allergol Int 2015; 64(2):175180.

21. Wesolowska-Andersen A, Seibold MA. Airway molecular endotupes of asthma: dissecting the heterogeneity. Cur Opin Allergy Clin Immunol 2015; 15(2):163-168.

22. Tartibi HM, Bahna SL. Clinical and biological markers of asthma control. Expert Rev Clin Immunol 2014; 10(11):1453-1461.

23. Pappas K, Papaioannou Al, Kostikas K, et al. The role of macrophages in obstructive airways disease: chronic obstructive pulmonary disease and asthma. Cytokine 2013; 64(3):613-625.

24. Gordon ED, Sidhu SS, Wang ZE, et al. A protective role for periostin and TGF-beta in IgE-mediated allergy and airway hyperresponsiveness. Clin Exp Allergy 2012; 42(1):144-155.

25. Bentley JK, Chen $Q$, Hong JY, et al. Periostin is required for maximal airways inflammation and hyperresponsiveness in mice. J Allergy Clin Immunol 2014; 134(6):1433-1442.

26. Sidhu SS, Yuan $S$, Innes $A L$, et al. Roles of epithelial cell-derived periostin in TGF-beta activation, collagen production, and collagen gel elasticity in asthma. Proc Natl Acad Sci U S A 2010; 107(32):14170-14175.

27. Johansson MW, Mosher DF. Integrin activation States and eosinophil recruitment in asthma. Front Pharmacol 2013; 4:33.

28. Choi JH, Kim MA, Park HS. An update on the pathogenesis of the upper airways in aspirinexacerbated respiratory disease. Curr Opin Allergy Clin Immunol 2014; 14(1):1-6.

29. Foster PS, Hogan SP, Ramsay AJ, et al. Interleukin 5 deficiency abolishes eosinophilia, airways hyperreactivity, and lung damage in a mouse asthma model. J Exp Med 1996; 183(1):195-201.

30. Kips JC, O'Connor BJ, Langley SJ, et al. Effect of SCH55700, a humanized anti-human interleukin-5 antibody, in severe persistent asthma: a pilot study. Am J Respir Crit Care Med 2003; 167(12):1655-1659.

31. Tartibi HM, Bahna SL. Clinical and biological markers of asthma control. Expert Rev Clin Immunol 2014; 10(11):1453-1461.

32. Corren J, Lemanske RF, Hanania NA, et al. Lebrikizumab treatment in adults with asthma. N Engl J Med 2011; 365(12):1088-1098.

33. Arron JR, Izuhara K. Asthma biomarkers: what constitutes a 'gold standard'? Thorax 2015; 70(2):105-7.

34. Sehra S, Yao W, Nguyen ET, et al. Periostin regulates goblet cell metaplasia in a model of allergic airway inflammation. J Immunol 2011; 186(8):4959-4966.

35. Li BL, Hou JJ, Nie FF, et al. Variations in expressions of periostin and related factors in early stage of wound healing and scar remodeling in rats. Zhonghua Wei Zhong Bing Ji Jiu Yi Xue 2013; 25(9):523-526.

36. Song JS, You JS, Jeong SI, et al. Serum periostin levels correlate with airway hyperresponsiveness to methacholine and mannitol in children with asthma. Allergy 2015; 70(6):674-681.

37. Konradsen JR, Skantz E, Nordlund B, et al. Predicting asthma morbidity in children using proposed markers of Th2-type inflammation. Pediatr Allergy Immunol 2015; 26(8):772-779. 